\title{
Biodiversity Patterns of
} Macroinvertebrate Assemblages in Natural and Artificial Lentic Waters on an Oceanic Island

\author{
Lucas Lamelas-López ${ }^{1}$, Paulo A. V. Borges ${ }^{1}$, Laura Serrano ${ }^{2}$, Vitor Gonçalves ${ }^{3}$ and \\ Margarita Florencio ${ }^{1,4,5,6 *}$ \\ ${ }^{1}$ CE3C - Centre for Ecology, Evolution and Environmental Changes/Azorean Biodiversity Group, Departamento de Ciências e \\ Engenharia do Ambiente, Universidade dos Açores, Açores, Portugal, ${ }^{2}$ Department of Plant Biology and Ecology, University \\ of Sevilla, Seville, Spain, ${ }^{3} \mathrm{CIBIO}$, Centro de Investigação em Biodiversidade e Recursos Genéticos, InBIO Laboratório \\ Associado, Pólo dos Açores, Faculdade de Ciências e Tecnologia, Universidade dos Açores, Ponta Delgada, Portugal, \\ ${ }^{4}$ Departamento de Ecologia, Universidade Federal de Goiás, Goiás, Brazil, ${ }^{5}$ Centro de Investigación en Biodiversidad y \\ Cambio Global (CIBC-UAM), Universidad Autónoma de Madrid, Madrid, Spain, ${ }^{6}$ Departamento de Ecología, Facultad de \\ Ciencias, Universidad Autónoma de Madrid, Edificio de Biología, Madrid, Spain
}

\section{OPEN ACCESS}

Edited by:

Elena D. Concepción, National Museum of Natural Sciences (MNCN), Spain

Reviewed by: Charl Deacon,

Stellenbosch University, South Africa Marina Reyne, Queen's University Belfast, United Kingdom

*Correspondence:

Margarita Florencio margarita.florencio@uam.es; mflorenciodiaz@gmail.com

Specialty section:

This article was submitted to Biogeography and Macroecology, a section of the journal Frontiers in Ecology and Evolution

Received: 11 September 2020 Accepted: 28 December 2020

Published: 25 January 2021

Citation:

Lamelas-López L, Borges PAV, Serrano L, Gonçalves $V$ and Florencio M (2021) Biodiversity

Patterns of Macroinvertebrate Assemblages in Natural and Artificial Lentic Waters on an Oceanic Island. Front. Ecol. Evol. 8:605176. doi: 10.3389/fevo.2020.605176
The Azorean islands have been historically affected by human activities, mainly due to the combined effects of habitat degradation and fragmentation, and the introduction of exotic species. We here aim to analyze the role of environmental characteristics and spatial descriptors in supporting regional biodiversity of macroinvertebrates by considering natural ponds and artificial tanks. After the monthly variation of macroinvertebrate assemblages was assessed in three temporary and two permanent ponds in the Azorean island of Terceira during a complete inundation-desiccation annual cycle, the assemblage differences of 12 ponds (three temporary and nine permanent ponds) and 8 closely-located artificial tanks were analyzed across a range of landscape disturbances. Macroinvertebrate assemblages were found to differ according to hydroperiod and sampled months. Although the former explained the highest variance, macroinvertebrate differentiation by hydroperiod was also dependent on the study month. Our results also revealed a consistent monthly pattern of species replacement. However, the contribution of nestedness to the macroinvertebrate $\beta$-diversity was notable when temporary ponds were close to desiccation, probably indicating a deterministic loss of species due to the impoverished water conditions of the ponds facing desiccation. When the macroinvertebrate assemblages were analyzed in relation to physico-chemical variations and spatial descriptors, the artificial tanks were not clearly segregated from the natural ponds, and only differentiated by pH differences. In contrast, those natural ponds exhibiting high concentrations of total phosphorous (likely signs of anthropization) also discriminated the ordination of ponds in a distance-based redundancy analysis, and showed impoverished assemblages in comparison with well-preserved ponds. The macroinvertebrate assemblages of the natural ponds showed a significant spatial pattern, but this spatial influence was not significant when tanks and ponds were considered together. Our results suggest that tanks may act as possible reservoirs of biodiversity during the desiccation period of temporary ponds, but are unable 
to establish successful populations. These fishless permanent tanks can complement the conservation of a biodiversity that is largely maintained by the pristine high-altitude natural ponds. The establishment of a guideline for conservation management that also considers the artificial tanks is necessary to benefit the local and regional Azorean macroinvertebrate diversity.

Keywords: beta-diversity, farm ponds, hydroperiod, landscape transformation, conservation, oceanic islands, pond water quality, temporary ponds

\section{INTRODUCTION}

Freshwater ecosystems are currently highly vulnerable to external perturbations associated with anthropogenic changes, mainly due to the introduction of exotic species, landscape transformations and climate change (Sala et al., 2000; Pyšek et al., 2010). Indeed, landscape transformation (e.g., to urban or agricultural areas) has largely contributed to the global loss and degradation of freshwater habitats and is a major threat to freshwater organisms (McKinney, 2002). In contrast to the general negative role of human disturbance in shaping biodiversity, artificial ponds or tanks associated with agricultural systems have sometimes demonstrated that they are able to sustain biodiversity (Abellán et al., 2006; Declerck et al., 2006; Céréghino et al., 2008; Thiere et al., 2009). These humanmade ponds usually have different environmental characteristics in comparison with natural ponds (e.g., Hill et al., 2016, but see Deacon et al., 2018, 2019 for similar chemical properties), given that these artificial systems usually have concrete sides and reduced vegetation cover, and possibly higher contaminant inputs compared to natural ponds (Hassall, 2014). Artificial ponds usually show reduced freshwater biodiversity, can support the occurrence of exotic species and may act as possible ecological traps (Oertli and Parris, 2019). However, artificial ponds that maintain good water quality (e.g., low concentrations of nutrient and other pollutants, vegetated bed/margins, low electrical conductivity) may provide habitat diversification, refuge and supplies for aquatic macroinvertebrates, amphibians, and terrestrial species (Mitsch and Gosselink, 2000; Oertli and Parris, 2019). Hence, artificial permanent waterbodies for cattle drinking-water have received increasing attention as regards conservation due to their secondary function as refuge habitat for macroinvertebrates (Ruggiero et al., 2008). In the current scenario of a changeable world, decisions regarding humanmade ponds are essential for conservation programs. However, the particular environmental conditions that favor or deplete biodiversity in artificial ponds across different land-uses, and their positive or negative contribution to biodiversity in a natural pond network remain quite unexplored.

Temporary ponds are characterized by recurrent inundation and desiccation (Williams, 1997; Florencio et al., 2011; Céréghino et al., 2012), but they can usually persist for centuries in the same region, in addition to possessing a worldwide distribution (Williams, 1997; Williams et al., 2001). However, the high and valuable biodiversity (high species richness in relation with the size of the pond, rare taxa, and uniqueness) of temporary ponds contrasts with their sensitivity and vulnerability to external perturbation (Williams, 2006). Consequently, temporary ponds are considered priority habitats for conservation by the European Union (code 3170 of the Habitat Directive). The inundation of temporary ponds usually starts at the onset of the rainy season, whereas the duration of the recurrent dry period is less predictable (Williams, 1997). These temporary ponds support singular macroinvertebrate taxa that often cannot survive in other types of aquatic ecosystems (Collinson et al., 1995; Bilton et al., 2001; Williams, 2006). The macroinvertebrate species that inhabit these ponds must cope with pond desiccation by adjusting their life cycles to the water permanence (hydroperiod) and employing particular strategies to survive pond desiccation (Williams, 2006). Moreover, these macroinvertebrates usually cannot cope with the presence of fish, having evolved in the absence of these top predators, which in most occasions are restricted to permanent ponds (Wellborn et al., 1996). In addition, the heterogeneity of a pond network is reflected in its hydroperiod gradient (Florencio, 2010). Therefore, widely variable hydroperiods, together with good pond connectivity, are key factors that contribute to the conservation of a high diversity of macroinvertebrates (Urban, 2004; Jeffries, 2005).

The proper management and conservation of biodiversity against possible threats require the acquisition of a good understanding of the regional species diversity, and the measurement of $\beta$-diversity is a useful concept to assess that (Socolar et al., 2016) as it allows the proper assessment of seasonal and spatial changes in aquatic invertebrate assemblage compositions (Florencio et al., 2016a). In metacommunity ecology, $\beta$-diversity may be defined as the variation in species composition among sites in a geographical region (Legendre et al., 2005; but see e.g., Koleff et al., 2003; Tuomisto, 2010; Anderson et al., 2011). The observed differences in $\beta$-diversity values may be the result of the combination of species between sites (replacement), and of the loss (or gain) of species between sites (nestedness), which it is known as a form of $\beta$-diversity partitioning (Baselga, 2010; Baselga and Orme, 2012). Alternatively, Carvalho et al. (2012) also provide this partition of $\beta$-diversity, but incorporate a richness difference component instead of nestedness. In ponds, those systems with high species replacement would demand the conservation of several ponds with variable richness and environmental conditions, while systems with low species replacement and high nestedness contribution to the $\beta$-diversity would prioritize the conservation of those ponds with the highest richness (see Baselga, 2010). 
The Azorean archipelago is an ideal model system to assess the impact of landscape alterations on biodiversity, given that the Azores has suffered intensive landscape transformations, as well as the introduction of exotic species (approximately $58 \%$ of the arthropods are exotic species; Borges et al., 2005). Such transformations from native to agricultural areas have drastically restricted the extent of the original native forests to high altitude areas, much less accessible to humans (Triantis et al., 2010; Borges et al., 2020). Natural freshwater ecosystems in Macaronesian archipelagos (Azores, Madeira, Selvagens, Canary Islands, and Cabo Verde, sensu Engler, 1914) are considered priority conservation areas by the EU Water Framework Directive (2000/60/EC) (WFD), and are mainly located in the high-altitude native forests. Although these ecosystems are essential for the conservation of a unique freshwater community, limited knowledge of their temporal and spatial dynamics hinders the establishment of proper conservation guidelines (Hughes and Malmqvist, 2005). The present study focuses on the landscape matrix of Terceira Island, Azores, where natural and artificial ponds are located, to analyze the role of environmental characteristics and humanmade ponds in supporting regional biodiversity. The spatiotemporal variations in the natural temporary and permanent ponds in Azores were first determined by using monthly data of three well-preserved temporary and two permanent ponds that were sampled monthly, during a complete year of inundationdesiccation cycling. Secondly, changes in macroinvertebrate assemblages were addressed across a range of anthropogenic disturbance, using all accessible ponds within Terceira Island as a study case, encompassing 12 natural ponds (three temporary and nine permanent ponds), and eight closely-located artificial tanks constructed to supply water for cattle. We hypothesized that (i) pond differences and seasonal variations in macroinvertebrate assemblages would indicate different pre-dominant taxonomical groups during the hydrological year, and that such differences would be explained by the pond characteristics; (ii) artificial tanks could act as reservoirs of aquatic biodiversity, and be inhabited by similar macroinvertebrate assemblages as natural ponds. To explore the latter, we have disentangled the environmental characteristics that favored macroinvertebrate diversity in these artificial tanks.

\section{MATERIALS AND METHODS \\ Study Site}

The Azores is an archipelago located in the North Atlantic, about $1,600 \mathrm{~km}$ from the European coast and 3,900 km from North America, between latitudes $36^{\circ} 55^{\prime}-39^{\circ} 43^{\prime} \mathrm{N}$ and longitudes $24^{\circ} 45^{\prime}-31^{\circ} 17^{\prime} \mathrm{W}$ (Figure 1). It comprises nine main islands and some islets, all of volcanic origin, which are organized in three groups: the western group (Corvo and Flores islands); the central group (Faial, Pico, São Jorge, Graciosa, and Terceira islands); and the Eastern group (São Miguel and Santa Maria islands). The climate is temperate oceanic, characterized by stable temperatures, substantial precipitation (mean annual precipitation of $740-2,400 \mathrm{~mm}$; Bettencourt, 1979) and high relative atmospheric humidity, which can reach more than 95\% in high-altitude native forests.

This study was carried out in Terceira Island which has an area of $402 \mathrm{~km}^{2}$ and a maximum elevation of 1,023 meters above sea level. The Azorean archipelago, and specifically Terceira Island, was colonized by the Portuguese in the 15 th century. Since the first settlements, the landscape was gradually transformed to accommodate agricultural activities and intensive pasturelands for cattle and crops after 1,950 (Triantis et al., 2010). Native forests were gradually destroyed as a consequence of these major land-use changes and currently the few remnants of the original forest or even secondary patches are located in the most inaccessible areas of the island (Figure 1), representing scarcely $6 \%$ of the Terceira Island surface area (Gaspar et al., 2008). Eight of the 12 studied ponds were located in natural and seminatural areas of Terceira Island, at between 387 and 912 m.a.s.l., including two protected areas with still pristine native forest, considered two of the most pristine areas in the Azores (Gaspar et al., 2011): "Caldeira de Santa Bárbara e Mistérios Negros" and "Terra Brava." These ponds are small $(<7,000$ $\mathrm{m}^{2}$ ) and shallow. The dominant aquatic vegetation is formed by the genera Juncus (Juncaceae), Eleocharis (Cyperaceae), and Sphagnum (Sphagnaceae), and by the species Littorella uniflora (Plantaginaceae), Hydrocotile vulgaris (Apiaceae), and Polytrichum commune (Polytrichaceae). The surrounding area is dominated mainly by native and endemic plants (e.g., Juniperus brevifolia, Laurus azorica, Ilex perado subsp. azorica, and Erica azorica), with a dominance of two types of forests: "JuniperusIlex Montane Forests" and "Juniperus Montane Woodlands" (Elias et al., 2016) that also include bryophyte communities on all substrates (Gabriel and Bates, 2005). The other four ponds and the eight tanks were located in human-modified landscapes (Figure 1, see details below).

Our study period was from November 2013 to August 2014. First, to understand the variations in the macroinvertebrate assemblages of the natural ponds on Terceira Island, monthly samples were collected in three temporary ponds (VF1, VF3, VF5) and two permanent ponds (NEG, SER) between November 2013 and August 2014 (Figure 1, see also Supplementary Figure 1, ESM1 in the Supplementary Material) (hereafter referred to as "monthly sampling"). These ponds were selected based on their hydroperiod gradient and spatial location within the protected area "Caldeira de Santa Bárbara e Mistérios Negros." Secondly, we sampled almost all natural ponds (12 out of the 16 known ponds as four of them were inaccessible; local names included in Supplementary Table 1, ESM1 in the Supplementary Material), and eight artificial tanks in Terceira Island in May 2014 (hereafter referred to as "extensive sampling") to assess the environmental characteristics that would determine differences in the macroinvertebrate assemblages across a gradient of landscape disturbance (Figure 1, see also Supplementary Figure 2, ESM1 in the Supplementary Material). The artificial tanks were located in agricultural areas, and were selected as the closest sites to a natural pond in order to consider their role as possible reservoirs of the aquatic fauna. The tanks have an artificial substrate of cement, with a surface area of 4-6 $\mathrm{m}^{2}$, and $0.4-1 \mathrm{~m}$ of maximum depth. 


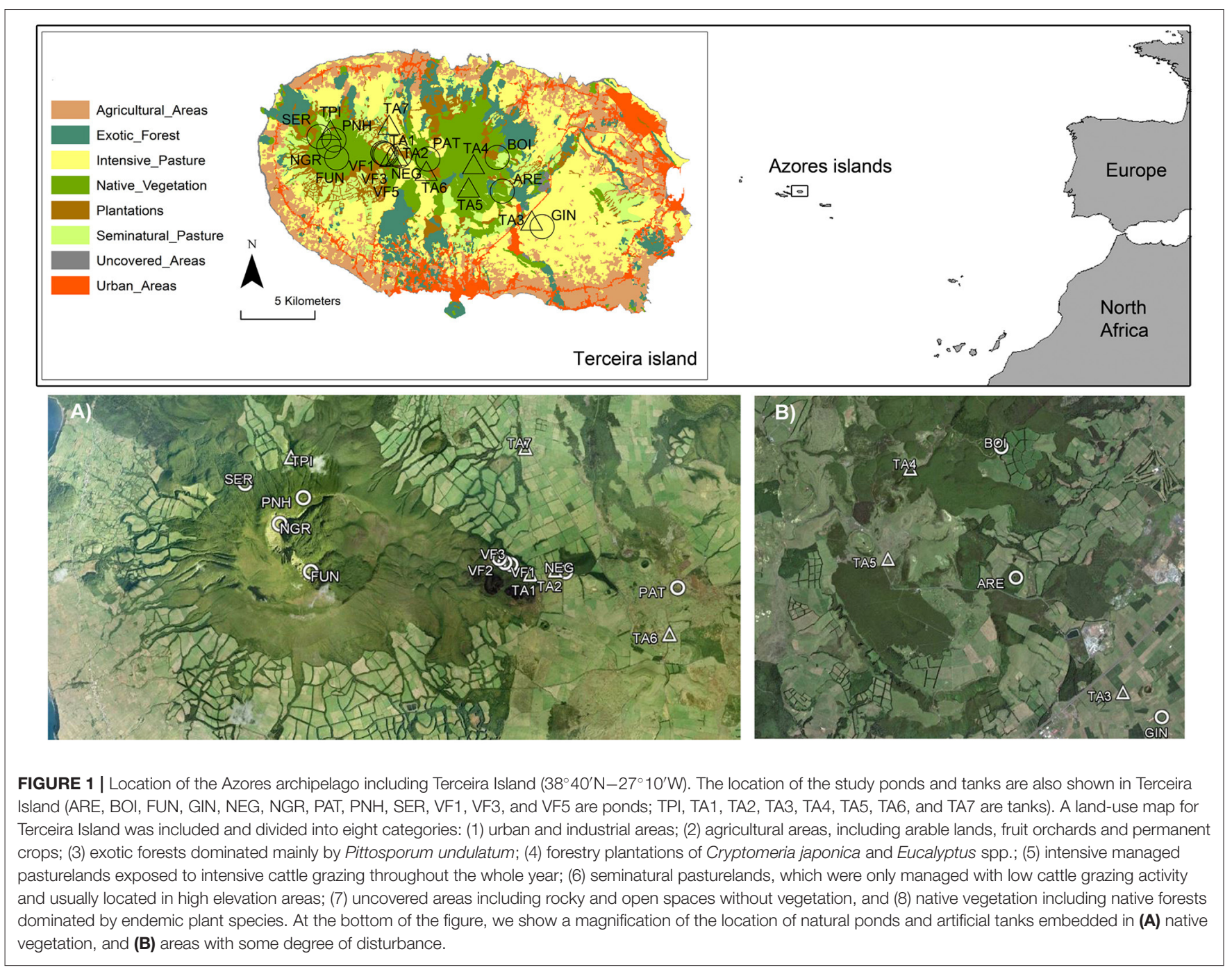

\section{Sampling Methods}

Macroinvertebrates were sampled using a dip net of $40 \times 25 \mathrm{~cm}$ with $1 \mathrm{~mm}$ mesh size. Approximately $1.5 \mathrm{~m}$ stretches of water were netted in each sampling unit, which encompassed three successive sweep nettings, collecting benthic, and open-water macroinvertebrates. Sampling was performed from the littoral zone to the deepest point of the pond when accessible, and considering different aquatic plant covers to include all the possible microhabitats. Because the dip netting efficiency seems to be better in small ponds (Heyer et al., 1994), the number of sampling units was proportional to the pond size (see Florencio et al., 2009). Hence, the number of samples per pond ranged from 5 to 19 sampling units. In total, 557 samples were obtained during the monthly sampling and 169 during the extensive sampling. Most individuals were sorted in the field, counted, and released, to minimize the researcher's impact in the field. Individuals of unidentified species were preserved in $70 \%$ ethanol for subsequent identification in the laboratory. Individuals were identified to species level, except for the genus Dryops which was identified to genus level, Culicidae to family level and
Oligochaeta to Class level; adult and larval stages were considered separately given their different ecological requirements (hereafter referred to as "species" for simplicity). The Dipteran family Chironomidae was not considered because of sampling and mesh size limitations.

\section{Physico-Chemical Characteristics and Land-Use Variables of Ponds}

The following environmental variables were measured in situ to characterize the study ponds during monthly and extensive samplings: electrical conductivity (EC) standardized at $20^{\circ} \mathrm{C}$ (Multi-range Conductivity meter HANNA HI 98127), $\mathrm{pH}$ (pH meter HANNA HI 98311), dissolved oxygen concentration, and temperature (Oxi 315i WTW) in the water column. Two replicates were obtained for each measurement per pond and month, but given the homogeneity in the measurements, the two pond values per month were averaged before statistical analyses. We also collected $1,500 \mathrm{ml}$ of the water column that was later filtered in the laboratory (Whatman GF/C filters, 
$47 \mathrm{~mm}$ diameter) to measure the concentrations of chlorophylla (spectrophotometric methods, Gonçalves, 2008), dissolved inorganic nitrogen (DIN) (following Golterman, 1991) and dissolved inorganic phosphate reactive to Mo (i-P) according to Murphy and Riley (1962). The concentration of total phosphorous in the water (TP) was also analyzed as i-P after acid digestion of the unfiltered water sample treated with $\mathrm{K}_{2} \mathrm{~S}_{2} \mathrm{O}_{8}$ (Golterman, 2004). DIN and i-P concentrations were only measured in the extensive sampling.

The land-use map of Terceira Island was constructed based on land-use cover classes of CORINE 2006 Land Cover (see Bossard et al., 2000) and DROTH (2008), at $30 \times 30$ meters resolution (Figure 1). The land-use map was divided into eight categories: (1) urban and industrial areas; (2) agricultural areas, including arable land, fruit orchards and permanent crops; (3) exotic forests dominated mainly by Pittosporum undulatum; (4) forestry plantations of Cryptomeria japonica and Eucalyptus spp.; (5) intensive managed pasturelands exposed to intensive cattle grazing throughout the whole year, characterized by common exotic grasses and leguminous forbs; (6) seminatural pasturelands, which were only managed with low cattle grazing activity and usually located in high altitude areas; (7) uncovered areas including rocky and open spaces without vegetation, and (8) native vegetation including native forests dominated by endemic plant species, but also including high-elevation anthropized pasturelands that have been abandoned and colonized by naturalized vegetation (native and exotic plants).

The percentage area occupied by the different land-uses in Terceira Island was calculated to quantify the impact of anthropogenic disturbance on the analyzed ponds and tanks. For this, each pond/tank center was established as the centroid of a 250-meter-radius buffer in order to estimate the local influence of the surrounding land-uses on the macroinvertebrate assemblages. Only intensively managed pasturelands, seminatural pasturelands and native vegetation surrounded the study ponds, and thus their percentage areas were considered as explanatory variables. The land-use map and the occupied percentage area calculation were performed using the GIS-based software ArcGIS 10 ArcMap v. 10.1.

\section{Spatial Variables Based on Interpond Distances}

Regarding the extensive sampling, we retained 11 orthonormal spatial descriptors of the 12 natural ponds and seven tanks ( $N=19$, one tank was excluded because no individuals were collected) using Principal Coordinates of Neighborhood Matrix (PCNMs) map distances. We used as truncation distance the longest distance among ponds to maintain pond connectivity (Borcard and Legendre, 2002). The extraction of these spatial descriptors was performed in R software 2.14.2, using the "pcnm" command in the "vegan" package (Oksanen et al., 2019).

\section{Data Analyses}

\section{Temporal Biodiversity Patterns}

For the monthly sampling data, abundance-based rarefaction, and sample-based rarefaction were used to determine the completeness of the natural pond inventories (see ESM2 in the
Supplementary Material). Given that differences in sampling efforts were not observed among the 5 monthly-sampled ponds (ESM2 in the Supplementary Material), raw data were used to perform all statistical analyses. To analyze the differences in the macroinvertebrate assemblage compositions among the sampled ponds and months, we constructed a matrix of species (columns) and ponds (rows) including all the sampling months by averaging the number of individuals of each species per each pond and month. Then, triangular matrices were obtained using the Bray-Curtis index of similarity (the inverse of the BrayCurtis index of dissimilarity). Assemblage similarity differences between ponds and months, as well as the possible interaction between these two factors (ponds $\times$ months), were analyzed using a two-way crossed permutational multivariate analysis of variance (PERMANOVA; Anderson, 2001). This non-parametric procedure allowed us to analyze differences between ponds and months based on the Bray-Curtis similarity distance. Statistically significant differences were tested using permutations of group membership; 9,999 permutations were performed using the software PRIMER v.6 (Anderson et al., 2008).

Differences in macroinvertebrate $\beta$-diversity patterns were investigated across the sampled months and ponds using presence-absence matrices and pooling adult and larval stages for each independent taxon. Then, triangular matrices were calculated using the Sørensen index of dissimilarity on the incidence data. The $\beta$-diversity partitioning approach proposed by Baselga (2010) was used to calculate the $\beta$-diversity patterns. Because the temporary ponds were drying out during the summer months, the per-month matrices varied in matrix size. Therefore, to determine $\beta$-diversity partitioning between ponds and to obtain comparable values of $\beta$-diversity for different matrix sizes, a multiple-site dissimilarity procedure was used (Baselga, 2012). To calculate the multiple-site $\beta$-diversity partitioning, the minimum number of ponds sampled in a month (three) was used to resample the total number of ponds sampled per month (1,000 random samples). To determine multiple-site $\beta$-diversity partitioning, the command "beta.sample" (betapart package, Baselga and Orme, 2012) was used, implemented in $\mathrm{R}$ software 2.14.2. Multiple-site $\beta$-diversity $\left(\beta_{\mathrm{SOR}}\right)$ was partitioned into two additive components that accounted for dissimilarity due to species replacement $\left(\beta_{\text {SIM }}\right)$ and dissimilarity due to nestedness $\left(\beta_{\mathrm{SNE}}\right)$, respectively, in accordance with the formula $\beta_{\text {SOR }}=\beta_{\text {SIM }}+\beta_{\text {SNE }}($ Baselga, 2010).

\section{Environmental and Land-Use Effects on Macroinvertebrate Assemblages}

Using monthly data, an environmental matrix per pond and month was constructed. With this matrix, triangular matrices of similarity were calculated using the Euclidean distance between each pair of ponds for each environmental variable. In order to analyze the environmental variables that influenced the monthly pattern of $\beta$-diversity, the multiple-site $\beta$-diversity partitioning, $\beta_{\text {SIM }}$ and $\beta_{\text {SNE }}$, were regressed against the average Euclidean distances of each environmental variables per month. A forward stepwise regression was performed following Blanchet et al. (2008), using the $\beta_{\text {SIM }}$ and $\beta_{\text {SNE }}$ per month as response-variables and the average Euclidean distances of the environmental 
variables per month $(N=10)$ as predictor variables. This complete procedure is considered to be an effective procedure for controlling Type I error (Peres-Neto and Legendre, 2010). These analyses were performed using the Statistica V.8 software.

Regarding the extensive sampling, environmental data and the land-use variables were used to construct a matrix including the 12 natural ponds and seven artificial tanks as cases. This matrix was used first to analyze the explanatory variables that determined the differences in macroinvertebrate assemblages of natural and artificial ponds. Secondly, a matrix was constructed that excluded the artificial tanks to analyze the explanatory variables that determined the differences in macroinvertebrate assemblages only among the natural ponds. The studied environmental variables were the concentration of TP, i-P, and DIN, electrical conductivity at $20^{\circ} \mathrm{C}$, dissolved oxygen concentration, $\mathrm{pH}$, and chlorophyll-a concentration in the water column. The studied land-use variables were the percentage area of native vegetation, seminatural pasturelands, and intensive pasturelands. All variables, with exception of $\mathrm{pH}$ and the land-use variables, were $\log (\mathrm{x}+1)$ transformed to satisfy normality assumptions. Triangular matrices were constructed using Euclidean distances of the environmental variables to determine if the explanatory variables (environmental and landuse characteristics) of ponds and tanks differed. Then, an ANOSIM analysis was performed using the aquatic systems (pond or tank) as factor, and 9,999 permutations for the significance level. Moreover, each individual variable was analyzed using a Student $t$-test, and alternatively a MannWhitney test when the normality assumption was not satisfied, to determine whether it differed significantly between natural ponds and artificial tanks. Moreover, in order to detect if the macroinvertebrate assemblages differed between ponds and tanks, a matrix was constructed including the average number of individuals of each species (columns) per pond (rows). Then, a triangular similarity matrix was built using the Bray-Curtis index on the abundance matrix. Subsequently, an ANOSIM test was performed using pond and tank as grouping factor, and 9,999 permutations to assess the significance level. Finally, an exploratory SIMPER analysis was performed to detect the species mainly contributing to the differences between ponds and tanks.

Furthermore, to investigate the impact of the explanatory variables and the spatial descriptors driving the macroinvertebrate assemblages across the extensive sampling, the relationship between the biological Bray-Curtis similarity matrix, the aforementioned matrix of transformed explanatory variables and the spatial descriptors (PCNMs) was analyzed. To do that, a resemblance matrix was also constructed based on Bray-Curtis similarity that excluded the tanks to analyze the variables driving the differences among the assemblages of ponds. We first visualized the relationship between all biological data and the explanatory variables as principal component ordinations using a distance-based redundancy analysis (dbRDA) (McArdle and Anderson, 2001), which constrains to linear combinations of the predictor variables (Anderson et al., 2008). A Student $t$-test, or alternatively a Mann-Whitney test, was performed, using the scores of the axes 1 and 2 of the dbRDA (dbRDA1 and dbRDA2) to analyze if they discriminated natural ponds and artificial tanks. Secondly, a distance-based linear model (DistLM) was performed for data partitioning (analogous to linear multiple regression) using forward stepwise and Adjusted $R^{2}\left(A d j R^{2}\right)$ criteria for variable selection. This procedure was performed separately for the aforementioned explanatory variables and for the spatial descriptors, retaining the significant variables that contributed to the dissimilarities of the macroinvertebrate assemblages. This DistLM model only included predictor variables that improved the explained sum of squares that would be expected by adding some random variable, taking into account the number of variables in the model (Anderson et al., 2008). We thus estimated the sequential partial increase in explained variability using the $A d j R^{2}$. The DistLM analysis was performed, first to analyze the differences between the tanks and natural ponds, and secondly, among the natural ponds alone. All these multivariate analyses were performed using the Primer V.6. software, the DistLM and dbRDA analyses were performed using the add-on package PERMANOVA+ (Anderson et al., 2008), while $t$-test and Mann-Whitney' test were performed in $\mathrm{R}$ software 2.14.2. In order to explore the partial contribution of the significant explanatory variables and the significant spatial descriptors (PCNMs) retained in the DistLM analyses on the macroinvertebrate assemblages, multiple regression on distance matrices (MRM) was performed, an extension of Mantel test (Legendre et al., 1994). We considered Spearman correlations $\left(r_{s}\right)$ and performed a forward-selection procedure to identify the significant variables (Legendre et al., 1994). The significance of the MRM models was assessed using 1,000 permutations using the "MRM" command ("ecodist" package, Goslee and Urban, 2007) in R software 2.14.2. Two successive models were constructed: (i) the environmental model, only using the significant explanatory variables to measure environmental influence on the macroinvertebrate assemblages, and (ii) the environmental + spatial model, using the significant PCNM spatial descriptors in addition to the explanatory variables to obtain partial effects. This procedure was performed for the considered tanks and natural ponds $(N=19)$, and among the natural ponds alone $(N=12)$.

\section{RESULTS}

\section{General Diversity Patterns}

A total of 4,247 individuals (3,295 individuals in the monthly study and 952 in the extensive study) were collected, belonging to 17 species; Basommatophora (1), Ephemeroptera (1), Odonata (3), Heteroptera (2), Coleoptera (9), and Trichoptera (1) (see ESM3 in the Supplementary Material). In the monthly sampling, temporary ponds had the highest species richness (temporary ponds $=13$ species, permanent ponds $=9$ species). In contrast, permanent ponds had the highest proportion of native individuals. Overall, temporary ponds had the highest occurrence of endemic species (represented by Hydroporus guernei Régimbart, 1891 - Dytiscidae and Limnephilus atlanticus Nybom, 1948 - Limnephilidae), and exhibited the highest proportion of endemic individuals. Temporary and permanent ponds had a similar small proportion of exotic individuals ( 1 and $0.8 \%$, respectively, Figure $2 \mathrm{~A}$ ). The seasonal pattern of macroinvertebrates revealed high abundance of the Fam. Dytiscidae, mainly consisting of the endemic H. guernei (61.3\%), 
with both adults and larvae detected across three different periods (November, February and May, see Figure 3, and ESM5 in the Supplementary Material). Moreover, the Families Libellulidae and Corixidae were also abundant when most temporary ponds were close to the desiccation (April and May, Figure 3).

Notably, natural ponds harbored the highest proportion of individuals of native (84\%) and endemic species (13\%), in comparison with the artificial tanks (79\% and $8 \%$, respectively). Exotic species were more frequent in tanks (13\%) in comparison with the natural ponds (3\%, Figure 2B). The two types of systems shared three exotic species, i.e., Helisoma trivolvis (Say, 1817), Helochares lividus (Forster, 1771), and Cercyon haemorrhoidalis (Fabricius, 1775). Additionally, individuals of the gastropods Planorbidae and the coleopterans Hydrophilidae were mostly detected in tanks, where only Culicidae and Baetidae individuals were found. In contrast, the nymphs of the odonates Coenagrionidae, Libellulidae and the endemic L. atlanticus were only detected in natural ponds (Figure 4).

\section{Temporal Biodiversity Patterns}

Significant effects of both pond and month factors were detected in the macroinvertebrate assemblages, as well as a significant interaction between these two factors (PERMANOVA, Pond Factor: Pseudo-F $=3.801$, P-value $<0.001$; Month Factor: Pseudo-F $=12.623$, P-value $<0.001$; Month $\times$ Pond Factor: Pseudo-F $=2.548$ P-value $<0.001)$. While pond explained a higher variance (14.47\%) than the month factor $(6.56 \%)$, the high explanatory variance of the interaction between the two factors, month and pond (13.38\%), indicated that the macroinvertebrate differences between ponds were dependent on the study month. Analyzing the monthly $\beta$-diversity partitioning, the contribution of species replacement to the $\beta$-diversity was higher than the contribution of the nestedness component across almost the whole seasonal pattern. However, in August, when most temporary ponds had dried out and permanent ponds had notably reduced their surface area, the value of the nestedness contribution to $\beta$-diversity increased, while the value of species replacement notably decreased (Figure 5).

\section{Environmental and Land-Use Effects on Macroinvertebrate Assemblages}

In the monthly sampling, the dissolved oxygen concentration, the TP concentrations, the electrical conductivity and the $\mathrm{pH}$ significantly explained the monthly pattern of species
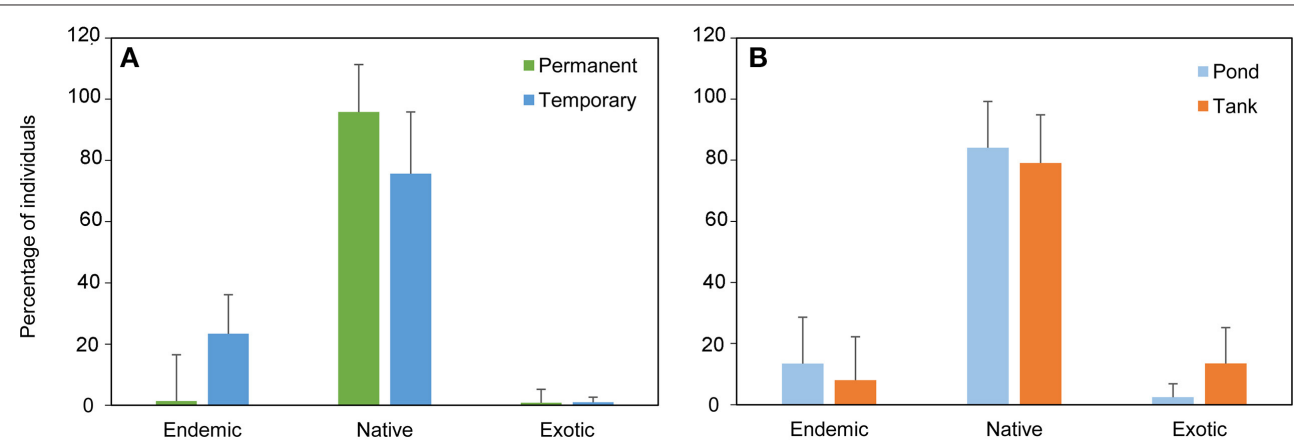

FIGURE 2 | Mean percentage of individuals of exotic, native and endemic species found (A) in the temporary and permanent ponds during the monthly sampling, and (B) in the natural ponds and artificial tanks during the extensive sampling.

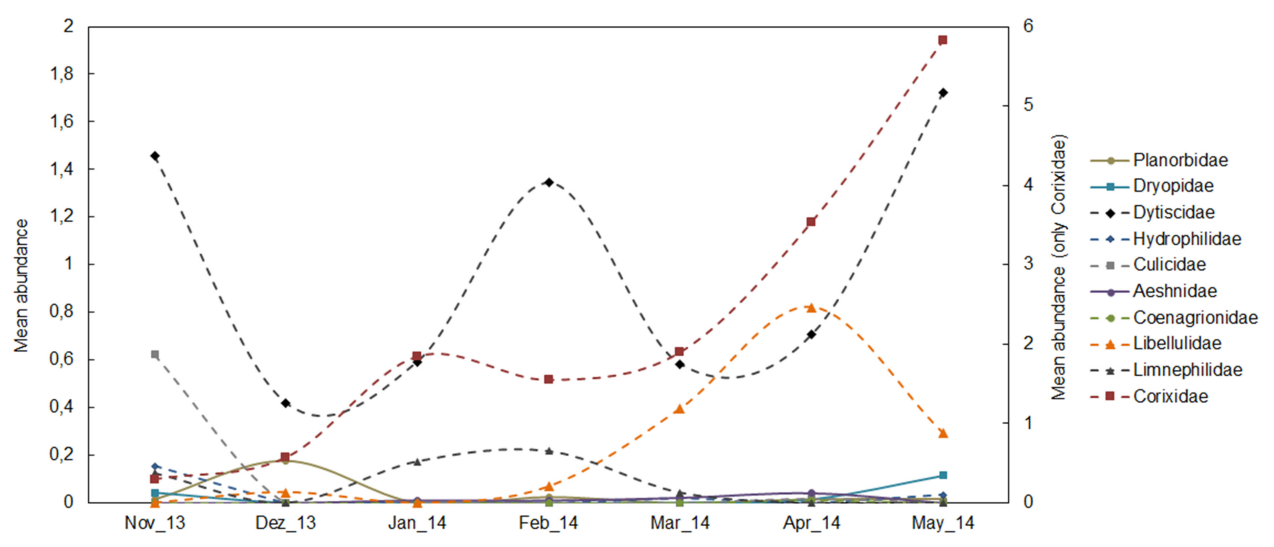

FIGURE 3 | Average number of individuals at the Family taxonomic level calculated per pond and month during the monthly sampling. Because of their high abundance, the Fam. Corixidae is indicated in an additional axis (see ESM4 in the Supplementary Material for details). 

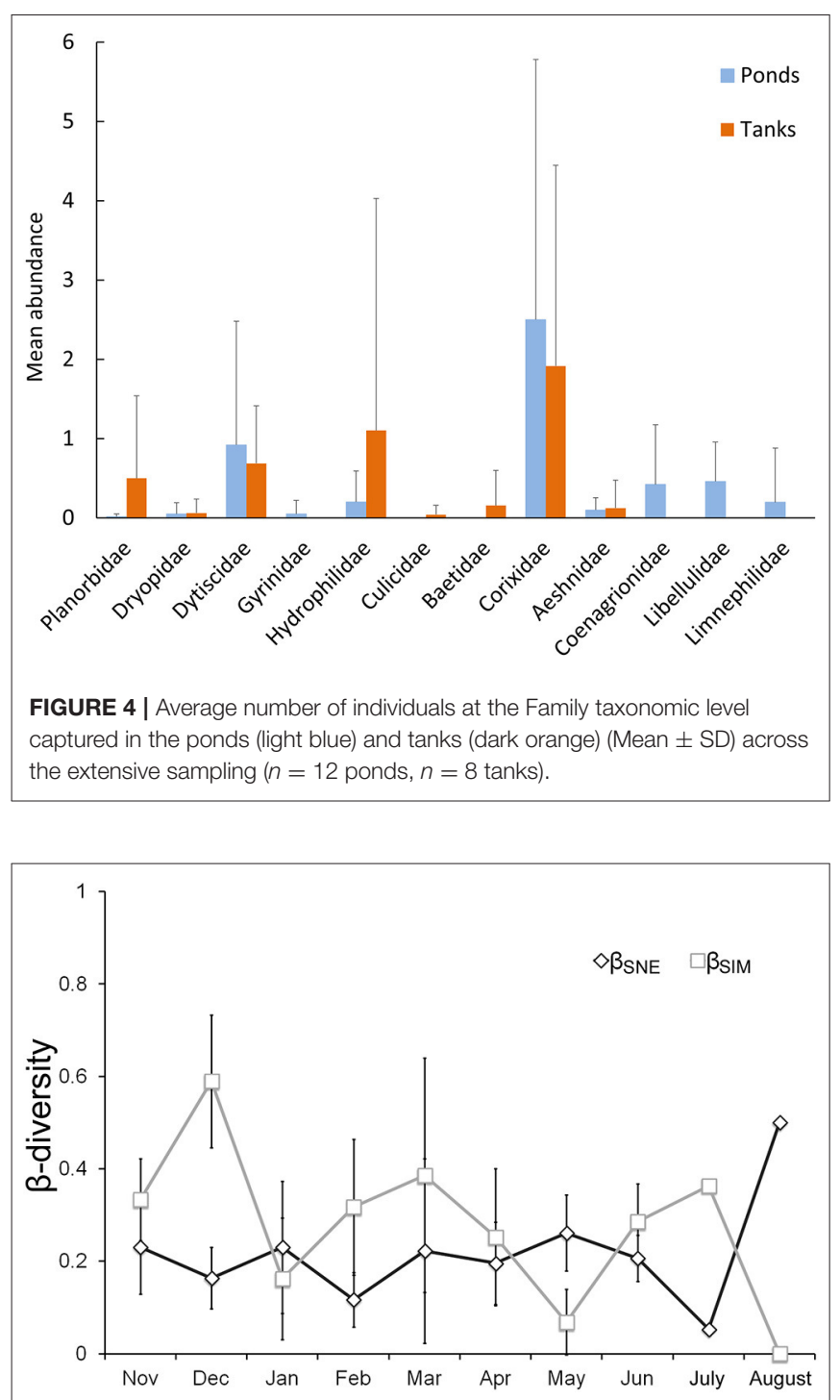

FIGURE 5 | Average values of the components of the macroinvertebrate $\beta$-diversity, the species replacement ( $\left.\beta_{\mathrm{SIM}}\right)$ and the contribution of the nestedness ( $\left.\beta_{\mathrm{SNE}}\right)$ to the $\beta$-diversity after $\beta$-diversity partitioning. Bars indicate the standard deviation (SD); July and August do not show SD because only a pair-wise comparison between the three ponds that maintained water by that time was performed.

replacement, while only chlorophyll-a concentration significantly explained the monthly pattern of the contribution of nestedness to the observed $\beta$-diversity (Table 1 ).

In the extensive sampling, the environmental variables indicated very low mineralization water and low DIN concentrations $\left(\leq 0.35 \mathrm{mg} \mathrm{L}^{-1}\right)$ in all sites, while only a few of them showed TP concentrations above $100 \mu \mathrm{g} \mathrm{L}^{-1}$ (Table 2). Natural ponds and artificial tanks markedly varied in the water $\mathrm{pH}$ ( $\mathrm{pH}_{\text {tanks }}$ 9.1-10.7, $\mathrm{pH}_{\text {ponds }}$ 4.3-7.0), while also showing significant differences in the concentration of dissolved oxygen ( $\mathrm{DO}_{\text {tanks }} \quad 7.80-13.35 \mathrm{mg} \mathrm{L} \mathrm{L}^{-1}, \mathrm{DO}_{\text {ponds }} 4.20-8.33 \mathrm{mg} \mathrm{\textrm {L } ^ { - 1 }}$ ), electrical conductivity $\left(\mathrm{EC}_{\text {tanks }} 60.5-135.0 \mu \mathrm{S} \mathrm{cm}{ }^{-1}, \mathrm{EC}_{\text {ponds }}\right.$
TABLE 1 | Monthly effects of the averaged Euclidean distances of the environmental variables on the components of the macroinvertebrate $\beta$-diversity partitioning, $\beta_{S I M}$ (species replacement) and $\beta_{S N E}$ (nestedness component), through multiple linear regression analysis.

\begin{tabular}{lcccc}
\hline $\begin{array}{l}\text { Environmental } \\
\text { variables }\end{array}$ & $\boldsymbol{P}$-value ( $\left.\boldsymbol{\beta}_{\text {SIM }}\right)$ & Wald Stat. & $\boldsymbol{P}$-value ( $\left.\boldsymbol{\beta}_{\text {SNE }}\right)$ & Wald Stat. \\
\hline Dissolved oxygen & 0.001 & 1.700 & 0.192 & 9.770 \\
pH & 0.006 & 0.664 & 0.415 & 7.435 \\
Electrical conductivity & 0.082 & 0.053 & 0.816 & 3.020 \\
Total phosphorous & 0.001 & 0.036 & 0.849 & 11.010 \\
Chlorophyll-a & 0.474 & 4.586 & 0.032 & 0.511
\end{tabular}

The P-values and the Wald statistic (Wald Stat.) are indicated.

28.8-79.5 $\left.\mu \mathrm{S} \mathrm{cm}^{-1}\right)$, and the percentage area occupied by natural vegetation ( $\mathrm{Nat}_{\text {tanks }} 0-59 \%$, Nat ponds $\left.0-100 \%\right)$ (Table 2). In most of the natural ponds, more than $98 \%$ of the surrounding area comprised natural vegetation (FUN, NGR, PHN, and SER). However, GIN pond was located in a disturbed area only surrounded by intensive pasturelands (Table 2). Tanks were located in pasturelands, most of them contiguous to natural ponds located in areas of native vegetation (Figure 1). The surrounding area of TPI, TA4, and TA 5 included $\sim 50 \%$ of native vegetation, while some tanks (e.g., TA3, TA6, and TA7) were located in areas dominated by intensive pasturelands (Table 2). Hence, significant differences in the environmental explanatory variables were observed between these two groups of ponds and tanks (ANOSIM, Global $R=0.979, P$-value $<0.001$ ). In contrast, statistically significant but weak differences were observed between the macroinvertebrate assemblages of the natural ponds and artificial tanks (ANOSIM, Global $R=0.186$, $P$-value $<0.05)$. The SIMPER analysis revealed that the only taxa with a contribution $>10 \%$ to this dissimilarity were the larvae of Corixa affinis and the Oligochaeta, mainly occurring in the artificial tanks (see ESM5 in the Supplementary Material).

In the dbRDA ordination, we observed that $\mathrm{pH}$ was the main difference between the assemblage compositions of ponds and tanks (Figure 6). The scores of axes 1 and 2 of the dbRDA significantly differed between natural ponds and tanks $(\mathrm{dbRDA} 1 \mathrm{t}=2.879, P$-value $<0.01 ; \mathrm{dbRDA} 2 \mathrm{~W}=38, P$ value $<0.0001)$. Hence, the DistLM analysis revealed that $\mathrm{pH}$ was the only significant variable explaining the differences among the macroinvertebrate assemblages of ponds and tanks (5\% of explained variability, Table 3). However, another four variables were also retained in the DistLM analysis, which explained 12\% of the total variability (Table 3 ). Only using natural ponds, the dbRDA1 axis could also discriminate them into two groups: the ponds with relatively high concentrations of DIN and dissolved oxygen, and mostly surrounded by native vegetation (group 1 : PHN, SER, FUN, NGR, NEG, VF1, VF3, and VF5 ponds), and those with high concentrations of TP and chlorophyll-a (group 2: GIN, PAT, BOI, and ARE ponds). When the DistLM analysis was performed only using these natural ponds, the concentration of TP in the water column was the single significant explanatory 
TABLE 2 | Environmental variables of the water column of the study ponds and tanks during the extensive sampling, measured in May 2014.

\begin{tabular}{|c|c|c|c|c|c|c|c|c|c|c|}
\hline & $\mathrm{DO}\left(\mathrm{mg} \mathrm{L}^{-1}\right)$ & $\mathrm{pH}$ & $\mathrm{EC}\left(\mu \mathrm{S} \mathrm{cm} \mathrm{cm}^{-1}\right)$ & $\mathrm{TP}\left(\mu \mathrm{g} \mathrm{L}^{-1}\right)$ & Chl. $\left(\mu \mathrm{g} \mathrm{L}^{-1}\right)$ & DIN (mg L-1) & $\mathrm{i}-\mathrm{P}\left(\mu \mathrm{g} \mathrm{L}^{-1}\right)$ & Nat (\%) & Sem $(\%)$ & Int (\%) \\
\hline \multicolumn{11}{|c|}{ Ponds } \\
\hline ARE & 7.13 & 5.2 & 49.5 & 65.53 & 15.17 & 0.039 & 1.00 & 23 & 3 & 22 \\
\hline $\mathrm{BOI}$ & 7.55 & 6.8 & 32.5 & 257.28 & 24.71 & 0.074 & 5.23 & 6 & 49 & 0 \\
\hline FUN & 8.33 & 5.5 & 28.0 & 49.27 & 2.06 & 0.089 & 1.82 & 100 & 0 & 0 \\
\hline GIN & 4.20 & 5.5 & 79.5 & 90.78 & 2.47 & 0.108 & 20.18 & 0 & 0 & 100 \\
\hline NEG & 7.00 & 7.0 & 37.8 & 99.03 & 5.49 & 0.168 & 0.64 & 6 & 52 & 0 \\
\hline NGR & 8.25 & 6.2 & 29.8 & 29.37 & 9.12 & 0.054 & 2.03 & 100 & 0 & 0 \\
\hline PAT & 7.10 & 5.6 & 38.8 & 104.86 & 17.06 & 0.108 & 1.39 & 69 & 31 & 0 \\
\hline $\mathrm{PNH}$ & 7.93 & 5.1 & 28.8 & 23.54 & 0.75 & 0.138 & 3.42 & 100 & 0 & 0 \\
\hline SER & 7.58 & 5.5 & 47.8 & 29.13 & 1.7 & 0.177 & 1.17 & 98 & 0 & 0 \\
\hline VF1 & 8.25 & 5.1 & 36.8 & 36.41 & 4.36 & 0.192 & 1.71 & 76 & 1 & 8 \\
\hline VF3 & 6.85 & 4.9 & 41.0 & 25.49 & 0.74 & 0.103 & 1.50 & 83 & 0 & 5 \\
\hline VF5 & 7.93 & 4.3 & 68.5 & 26.94 & 22.12 & 0.350 & 3.63 & 83 & 0 & 5 \\
\hline \multicolumn{11}{|c|}{ Tanks } \\
\hline TPI & 10.70 & 9.9 & 60.5 & 153.64 & 64.36 & 0.237 & 2.24 & 46 & 31 & 0 \\
\hline TA1 & 9.95 & 10.0 & 87.0 & 28.64 & 21.42 & 0.034 & 1.60 & 32 & 47 & 1 \\
\hline TA2 & 7.80 & 9.2 & 51.5 & 44.42 & 2.06 & 0.069 & 2.03 & 9 & 71 & 0 \\
\hline TA3 & 9.75 & 10.0 & 135.0 & 90.53 & 2.06 & 0.074 & 22.53 & 0 & 0 & 100 \\
\hline TA4 & 8.60 & 9.1 & 97.5 & 48.30 & 2.88 & 0.030 & 1.28 & 57 & 43 & 0 \\
\hline TA5 & 11.20 & 10.3 & 112.5 & 35.68 & 31.58 & 0.079 & 6.09 & 59 & 41 & 0 \\
\hline TA6 & 10.00 & 10.2 & 103.5 & 123.79 & 5.88 & 0.000 & 5.55 & 41 & 0 & 53 \\
\hline TA7 & 13.35 & 10.7 & 106.5 & 55.83 & 2.88 & 0.000 & 5.98 & 0 & 18 & 59 \\
\hline Diff & $-4.21^{\star \star \star}$ & $-14.86^{\star \star \star}$ & $-5.28^{\star \star \star}$ & $-0.57_{\text {n.s. }}$ & $-0.66_{\text {n.s. }}$ & $1.95_{\text {n.s. }}$ & $-1.16_{\text {n.s. }}$ & $2.16^{\star}$ & $28_{\text {n.s. }}$ & 41.5n.s. \\
\hline
\end{tabular}

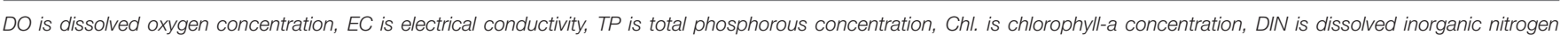

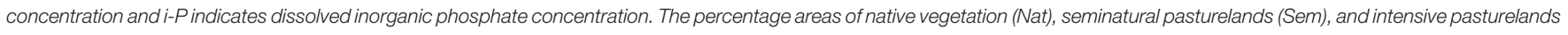

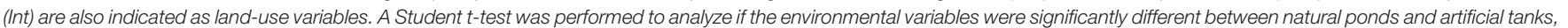

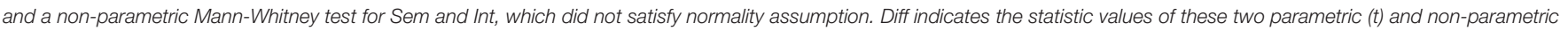
W) tests, respectively; the $P$-values are also indicated as ${ }^{*}<0.05,{ }^{\star \star}<0.01,{ }^{\star \star \star}<0.001$; all the non-significant differences were P-values $>0.06$ (indicated as $n$.s.).

variable ( $10 \%$ of explained variability, Table 3$)$. However, another three variables were retained in the DistLM analysis, which explained $21 \%$ of the total variability (Table 3 ).

\section{Environmental Variables vs. Spatial Descriptors}

In the extensive sampling, seven out of the 11 spatial descriptors were retained in the DistLM analysis. Only the PCNM7 had a significant influence on the macroinvertebrate assemblages (Table 3). However, when the partial effect of the PCNM7 was analyzed taking into account the $\mathrm{pH}$, the model revealed that only the $\mathrm{pH}$ was significant in explaining the dissimilarity of the macroinvertebrate assemblages (Table 4). When the DistLM analysis was repeated with only the natural ponds, two significant spatial descriptors (PCNM2 and PCNM5) were detected out of the five PCNMs retained. The partial effect of these two spatial descriptors, taking into account the concentration of TP in the water column, revealed the important effect of these two PCNMs on the dissimilarities in the macroinvertebrate assemblages, as they explained $34 \%$ of the total variability in the environmental + spatial model (Table 4).

\section{DISCUSSION}

In order to understand the extent of the anthropogenic influence on the unique freshwater ecosystems of Macaronesia, we have first investigated the ecological dynamic of these singular ecosystems and their macroinvertebrate assemblages. In the Azorean island of Terceira, a consistent seasonal pattern of macroinvertebrate species replacement has been detected across a hydroperiod gradient that disappeared when most temporary ponds were desiccated in summer. This desiccation period was thus observed to be an important factor for the community structure of the Azorean macroinvertebrates, as occurs in other sensitive regions of temporary pond networks, such as in Mediterranean-climate areas (Florencio et al., 2011). The role of artificial tanks as possible reservoirs for macroinvertebrates might be especially relevant as refuges during aestivation for those organisms inhabiting temporary ponds, which need to cope with pond desiccation in summer (see Deacon et al., 2019; Samways et al., 2020). Our results suggest that the studied artificial tanks maintain good water quality and are suitable for macroinvertebrate species, thus increasing the heterogeneity of habitats as permanent waterbodies in the peak of the hydroperiod gradient. This is even more important if we consider that 


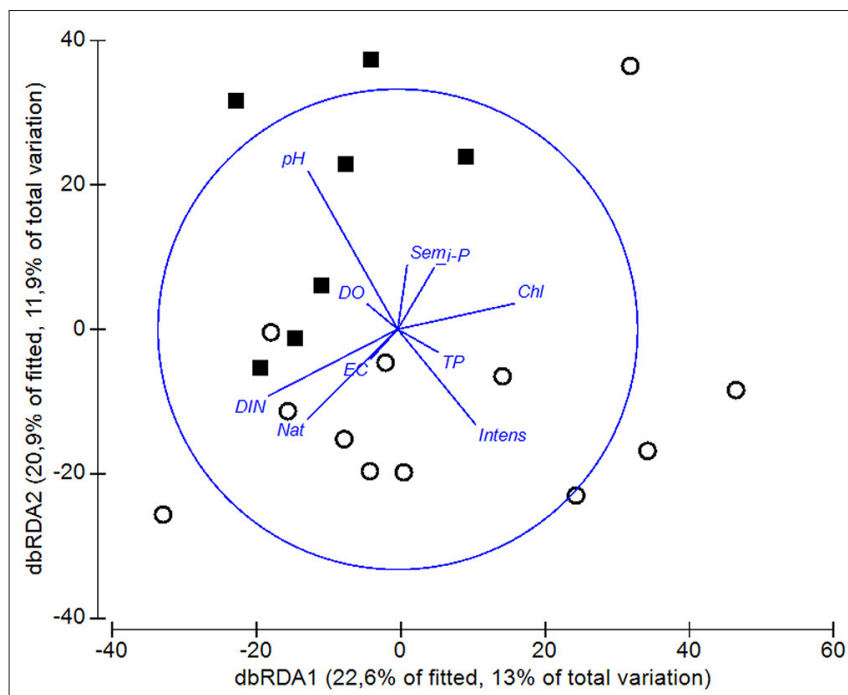

FIGURE 6 | Distance-based RDA ordination relating the explanatory variables with the macroinvertebrate assemblages, using the Bray-Curtis similarity index. The length and direction of the vectors represent the strength and direction of the relationship. DO is dissolved oxygen concentration, EC is electrical conductivity, TP is total phosphorous concentration, Chl is chlorophyll-a concentration, DIN is dissolved inorganic nitrogen concentration, $\mathrm{i}-\mathrm{P}$ is dissolved inorganic phosphate concentration. For the land-use variables, Nat is the percentage area of native vegetation, Sem is the percentage area of seminatural pasturelands, and Intens is the percentage area of intensive pasturelands. Squares indicate the artificial tanks and open circles the natural ponds.

fishless permanent waterbodies are scarce in the Azorean islands (Florencio and Lamelas-López, 2016; Raposeiro et al., 2017).

\section{Characteristics of The Azorean Natural Ponds}

The natural ponds in Terceira Island were characterized by well-oxygenated and slightly acidic waters, with low values of conductivity, which indicates that the ponds are primarily flooded with rainwater (Florencio and Lamelas-López, 2016). Differences in macroinvertebrate composition among ponds were observed to be higher than seasonal differences (monthly), which can be associated with the limited fluctuations in temperatures throughout the year under a temperate oceanic climate. This result contrasts with the typical seasonal variations of European ponds, where changes in the environmental characteristics are reflected in seasonal variations of assemblage compositions (e.g., Jeffries, 2003). Seasonal differences among ponds in the macroinvertebrate assemblages reflected the desiccation of the temporary ponds and the reduction of the water level in the permanent ponds. Interestingly, the larvae and adults of the endemic beetle $H$. guernei peaked three times during the hydrological cycle of temporary ponds, i.e., November (after pond inundation), February, and May (close to pond desiccation). This result seems to indicate at least three successive periods of reproduction for this species, which is important for conservation regarding: (1) the Endangered category of this species in the IUCN Red List of Threatened Species (Borges et al., 2018), and (2) the protected character of these high-altitude natural ponds in the Azores. We acknowledge that a strong signal of seasonal variation in assemblage composition was detected though the number of ponds was low. It is likely, then, that the sampled ponds provided a good representation of the study area.

Seasonal $\beta$-diversity patterns revealed that the differences in assemblage compositions were mainly associated with species replacement, and that pond desiccation favored the contribution of nestedness to the observed $\beta$-diversity, a pattern that has also been found in other temporary pond networks (Florencio et al., 2011, 2016a). The seasonal variation of the dissolved oxygen and TP concentrations, electrical conductivity and $\mathrm{pH}$ determined the seasonal changes in species replacement, probably associated with the variation in the timing and amount of rainfall. However, the proximity to the dry-period increased the contribution of nestedness to the $\beta$-diversity and also reduced species replacement. Close to pond desiccation, high concentrations of TP and chlorophyll-a were reached in concordance with a reduction in the inundated surface area, which also seemed to influence the $\mathrm{pH}$ and electrical conductivity of the water. Pond desiccation is an asynchronous process within a temporary pond network, as it depends on the hydroperiod of each pond. In Mediterranean ponds, water depth and electrical conductivity have also been detected as key variables explaining changes in assemblage composition and $\beta$-diversity associated with species replacement (Florencio et al., 2014). In our results, most temporary ponds were desiccated in August, when the values of nestedness contribution to $\beta$-diversity were maximal, mainly influenced by a high chlorophyll-a concentration. Fish were detected in the only two permanent ponds that held water during August during the study period (Florencio and LamelasLópez, 2016), and these were the only ponds that were able to act as refuge for macroinvertebrates in summer.

\section{Artificial Tanks as Reservoirs for Biodiversity}

Fishless artificial tanks associated with agricultural systems acquire an important role in preserving the macroinvertebrate assemblages of Azorean ponds. This possibility is supported by the similar composition that has been detected in the macroinvertebrate assemblages of ponds and tanks, with only small variations explained by the notably higher $\mathrm{pH}$ of artificial tanks. This could be explained by the longer persistence of water, smaller rain catchment (i.e., smaller basin) and the construction materials of the tanks (basic materials; Hassall, 2014). Hence, the high $\mathrm{pH}$ values in tanks could have favored the gastropods of the Fam. Planorbidae (e.g., Şahin and Zeybek, 2016). The conservation of macroinvertebrates in artificial tanks was also supported by their low concentration of nutrients and chlorophyll-a, reflecting a low probability of eutrophication (see Campbell et al., 2009). Consequently, tanks can be considered potential suitable habitats for at least 10 species of macroinvertebrates (see ESM3 in the Supplementary Material). Notably, some native species were only captured in tanks, such as the beetles Hygrotus confluens (Fabricius, 1787) or the single species of the Ephemeroptera order known in Azores, Cloeon 
TABLE 3 | Partial effects of the explanatory variables (Environmental) and the spatial descriptors based on PCNMs (Spatial) using distance-based linear models (DistLM), performing a forward stepwise process based on the Adjusted $R^{2}\left(A d j R^{2}\right)$.

\begin{tabular}{|c|c|c|c|c|c|c|c|}
\hline Environmental & $\operatorname{Adj} R^{2}$ & Pseudo-F & $P$-value & Spatial & $\operatorname{Adj} R^{2}$ & Pseudo-F & $P$-value \\
\hline \multicolumn{8}{|l|}{ Ponds vs. tanks } \\
\hline $\mathrm{pH}$ & 0.049 & 1.935 & $<0.05$ & PCNM7 & 0.042 & 1.789 & $<0.05$ \\
\hline TP & 0.084 & 1.634 & 0.085 & PCNM11 & 0.080 & 1.711 & 0.064 \\
\hline Nat & 0.094 & 1.191 & 0.292 & PCNM4 & 0.094 & 1.244 & 0.289 \\
\hline Chl & 0.101 & 1.103 & 0.356 & PCNM5 & 0.105 & 1.188 & 0.290 \\
\hline \multirow[t]{3}{*}{ DIN } & 0.117 & 1.257 & 0.260 & PCNM3 & 0.116 & 1.174 & 0.324 \\
\hline & & & & PCNM8 & 0.128 & 1.176 & 0.325 \\
\hline & & & & PCNM6 & 0.144 & 1.224 & 0.281 \\
\hline \multicolumn{8}{|l|}{ Only ponds } \\
\hline $\mathrm{TP}$ & 0.099 & 2.205 & $<0.05$ & PCNM2 & 0.123 & 2.541 & $<0.05$ \\
\hline Sem & 0.163 & 1.768 & 0.077 & PCNM5 & 0.215 & 2.169 & $<0.05$ \\
\hline $\mathrm{i}-\mathrm{P}$ & 0.165 & 1.022 & 0.411 & PCNM4 & 0.287 & 1.917 & 0.079 \\
\hline \multirow[t]{2}{*}{ DO } & 0.210 & 1.454 & 0.182 & PCNM6 & 0.290 & 1.029 & 0.417 \\
\hline & & & & PCNM7 & 0.302 & 1.123 & 0.362 \\
\hline
\end{tabular}

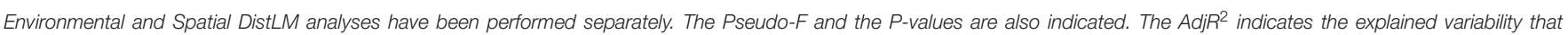

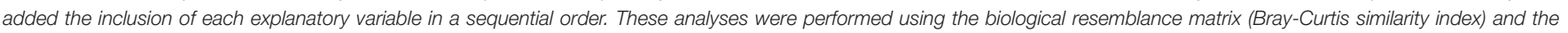

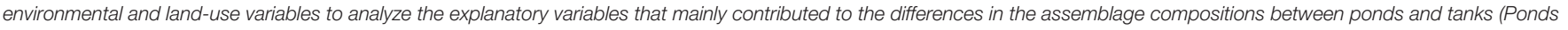

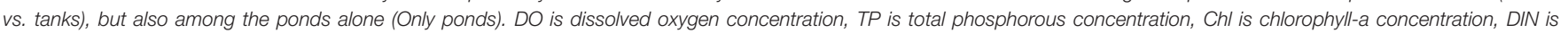

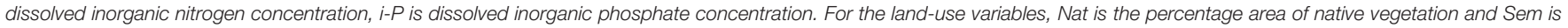
the percentage area of seminatural pasturelands.

TABLE 4 | Multiple regression models (MRM) revealing the partial contribution of the spatial descriptors (PCNMs) and the explanatory variables to the dissimilarity in the macroinvertebrate assemblages, between ponds and tanks (Ponds vs. tanks), but also among the ponds alone (Only ponds).

\begin{tabular}{lccc}
\hline Variable & $\boldsymbol{r}^{2}$ & $\boldsymbol{r}_{\mathbf{s}}$ & $\boldsymbol{P}$-value \\
\hline Ponds vs. tanks & & & $<0.05$ \\
Environmental & 0.030 & & $<0.05$ \\
pH & & 0.173 & 0.170 \\
Environmental + Spatial & 0.046 & & $<0.05$ \\
pH & & 0.186 & 0.382 \\
PCNM7 & & 0.128 & $<0.05$ \\
Only ponds & & & $<0.05$ \\
Environmental & 0.199 & 0.446 & $<0.01$ \\
TP & & & $<0.05$ \\
Environmental + Spatial & 0.344 & 0.265 & $<0.05$ \\
TP & & 0.422 & \\
PCNM7 & & & \\
\hline
\end{tabular}

We only used those retained variables that were significant in the DistLM analyses (see Table 3), including only the explanatory variables (Environmental) in the MRM model, and including the spatial descriptors in this model (Environmental + Spatial). TP is total phosphorous concentration in the water column, $r^{2}$ is the model explanatory capacity (ranged 0-1), $r_{s}$ indicates the coefficients of Spearman correlations.

dipterum (Linnaeus, 1761). This is possibly associated with the preference of these species for higher water temperature, as has been registered in tanks (see Stauder, 1991; McKee and Atkinson, 2000). In Azores, Ephemeroptera mainly occurs in human-made systems (Brinck and Scherer, 1957), contributing to increase the total biodiversity. We also found adults and larvae of the endemic species Hydroporus guernei and larvae of the
Limnephilus atlanticus (Borges et al., 2010) in tanks, although these species were mainly recorded in natural temporary ponds. Other species can benefit from the long hydroperiod of artificial tanks, such as the dragonfly Anax imperator Leach, 1815 (Fam. Aeshnidae), which usually prefers permanent waters to develop its instars and complete metamorphosis (see Corbet, 1957). However, natural ponds harbored the highest proportion of individuals belonging to native non-endemic and endemic species, most of which ( 8 out of 13 species) were also detected in artificial tanks. Additionally, although exotic species were more frequently detected in tanks (13\% of all the collected individuals in tanks belong to exotic species), these exotic species do not seem to have so far successfully colonized natural ponds, which are only harboring $3 \%$ of individuals belonging to exotic species. This is probably due to the pristine conditions of habitats surrounding the natural ponds. However, the artificial tanks had a higher proportion of exotic species than natural ponds despite the short distance between them (180-2,130 meters). It is possible that, due to their location in the pristine native forests, the natural ponds could be able to resist the invasion of exotic species (i) as well-preserved communities (biotic resistance to invasion, sensu Elton, 1958), (ii) because high-altitude native forests could act as physical barriers to the colonization of exotic species (Florencio et al., 2016b), (iii) and possibly also due to the temporary character of some natural ponds, which harbor a singular fauna adapted to pond desiccation (Williams, 2006). Hence, when comparing two distinct types of systems (natural vs. artificial), the macroinvertebrate dissimilarities between them seemed to be lower than those found between ponds located in well-preserved areas and those with signs of anthropogenic disturbance. The former group exhibited slightly higher concentrations of DIN and dissolved oxygen, which could be related to a different 
exposure to the wind, given that these ponds are generally located at higher altitude in the native forest. The latter group of ponds were associated with human activities, located at lower altitude where agricultural activities and cattle ranching are more common, which was reflected in the slightly higher concentrations of TP and chlorophyll-a. Nonetheless, both natural ponds and tanks exhibited a relatively low concentration of nutrients (DIN and TP) that fell within the range of other wetlands and ponds located in protected areas of comparable rainfall regimes (Plenzler and Michaels, 2015).

Natural ponds displayed a high degree of endemicity that was mainly associated with temporary ponds, and a low species richness of macroinvertebrates. These two phenomena of high endemicity and "disharmony" (impoverished biota in comparison with the adjacent mainland, even lacking entire taxonomical groups) are typical of the insular biota, and have been described for the freshwater invertebrates of the Azores (Raposeiro et al., 2012; Florencio and Lamelas-López, 2016). The macroinvertebrate assemblages of these natural ponds were spatially structured, but this spatial pattern was not detected when tanks and ponds were considered together. This result suggests that the aquatic organisms benefit from tanks as refuges (e.g., to cope with the desiccation of temporary ponds), though they are not suitable habitats to establish successful populations (but see Svensson, 1977).

\section{CONCLUSIONS}

Despite storing water for livestock farming, it has been shown that artificial tanks can play a beneficial role in preserving macroinvertebrate assemblages. These freshwater systems of anthropogenic origin can harbor a wide range of taxa (see Hassall, 2014; Hill et al., 2015), enhancing regional diversity without replacing the essential conservation value of natural ponds (Reyne et al., 2020). In the present study, the artificial tanks in Terceira Island provided permanent waters that were able to harbor endemic and native species, increasing the heterogeneity of habitats along the hydroperiod gradient. The good water quality of the study tanks has also been shown, as they exhibited low concentrations of nutrients and chlorophyll-a, and low conductivity. These tanks increased the regional biodiversity despite their concrete walls without aquatic vegetation, both considered possible disruptive elements for macroinvertebrate diversity in urban/rural ponds (Oertli and Parris, 2019). However, we suggest that these concrete walls could have prevented grazing cattle from entering the water, which can significantly affect water quality (Campbell et al., 2009). Nevertheless, the occurrence of submerged and littoral vegetation might provide food, refuge and structure (e.g. for reproduction) for some macroinvertebrates (Fuentes-Rodríguez et al., 2013) and amphibians (Swartz and Miller, 2019). In our study, the lack of aquatic vegetation in the tanks could have prevented the proper establishment of odonate species (see Foote and Hornung, 2005; Hykel et al., 2020), as well as the occurrence of other aquatic species (e.g., aquatic beetle and bug species, see Deacon et al., 2018). Additionally, it is not known if tanks located at greater distances from the protected areas would also act as refuge habitats of macroinvertebrate assemblages.
Our study suggests some recommendations to preserve the macroinvertebrate diversity of the Azorean ponds. (1) Maintain optimal environmental conditions in tanks like those found in natural and non-disturbed ponds (except for the $\mathrm{pH}$ of the water, due to the nature and physical structure of the tanks). (2) Maintain a high level of conservation of the pristine areas that contain the natural ponds, which allow most species to develop their life cycles and sustain high biodiversity, and protect these ponds against the arrival of potential invaders (see Samways et al., 2020). (3) The identification of anthropogenic pressures on the most disturbed ponds is essential to establish management strategies for conservation, mainly in the agricultural areas. (4) Further studies should evaluate possible strategies for the management of the artificial tanks to establish suitable conservation guidelines at local and landscape scales, that integrates both artificial tanks and natural ponds. Some examples of these strategies may be the inclusion of aquatic vegetation in the artificial tanks, as well as building facilities in their concrete walls (e.g., ramps) to favor the entrance/exit of some aquatic organisms. (5) The design of corridors from highaltitude native forests to the coast (see Aparício et al., 2018), including some of the study ponds and close-located tanks, could promote the conservation of the aquatic macroinvertebrates of the Terceira Island. We also highlight the importance of conducting seasonal studies that cover complete inundationdesiccation periods of ponds to properly represent the entire macroinvertebrate community, and to establish appropriate guidelines for conservation regarding the whole community. The singularity and vulnerability of the Azorean ponds must be highlighted, mainly regarding the scarce number of temporary ponds in Terceira Island, and we recommend including them in conservation programs, such as the Ramsar Convention.

\section{DATA AVAILABILITY STATEMENT}

The original contributions presented in the study are included in the article/Supplementary Material, further inquiries can be directed to the corresponding author.

\section{AUTHOR CONTRIBUTIONS}

MF and LL-L conceived the idea. LL-L performed the field sampling with the help of MF. VG and LS carried out some chemical determinations in the laboratory. LL-L and MF wrote the manuscript with significant contributions by $\mathrm{PB}$, and all the authors revised the different versions of the manuscript.

\section{FUNDING}

We are grateful to the Fundación Barrie for the academic fellowship of LL-L. MF's grant has been funded by the Conselho Nacional de Desenvolvimento Científico e Tecnológico - CNPq (401045/2014-5), program Ciência sem Fronteiras. MF's current contract was supported by the Universidad Autónoma de Madrid. MF is also grateful to the project ClimaRiskinPond (PID2019-104580GA-I00/AEI/10.13039/501100011033) funded 
by the Spanish Ministerio de Ciencia e Innovación, and PB was supported by the project FCT-UIDB/00329/2020.

\section{ACKNOWLEDGMENTS}

We are grateful to Rui Elias and Rosalina Gabriel who provided the technical equipment for $\mathrm{pH}$, dissolved oxygen concentration, and electrical conductivity measurements in the water column. We also appreciate the contributions of Adolfo Cordero for his support and comments, and to Herlander Lima for performing some chemical analyses in the laboratory. We are also grateful to Luis Ansias, Jose Sarangollo, Herlander Lima, Raquel Daza, Lucía Lamelas, David Rodilla, Fernando Pereira, and Paco Gutiérrez for their assistance in fieldwork.

\section{SUPPLEMENTARY MATERIAL}

The Supplementary Material for this article can be found online at: https://www.frontiersin.org/articles/10.3389/fevo. 2020.605176/full\#supplementary-material

\section{REFERENCES}

Abellán, P., Sanchez-Fernández, D., Millán, A., Botella, F., Sánchez-Zapata, J. A., and Giménez, A. (2006). Irrigation pools as macroinvertebrate habitat in a semi-arid agricultural landscape (SE Spain). J. Arid Environ. 67, 255-269. doi: 10.1016/j.jaridenv.2006.02.009

Anderson, M. J. (2001). A new method for non-parametric multivariate analysis of variance. Austral. Ecol. 26, 32-46. doi: 10.1046/j.1442-9993.2001.01070.x

Anderson, M. J., Crist, T. O., Chase, J. M., Vellend, M., Inouye, B. D., Freestone, A. L., et al. (2011). Navigating the multiple meanings of $\beta$ diversity: a roadmap for the practicing ecologist. Ecol. Lett. 14, 19-28. doi: 10.1111/j.1461-0248.2010.01552.x

Anderson, M. J., Gorley, R. N., and Clarke, K. R. (2008). PERMANOVA+ for PRIMER: guide to software and statistical methods. Plymouth: PRIMER-E.

Aparício, B. A., Cascalho, J., Cruz, M. J., Borges, P. A. V., Azevedo, E. B., Elias, R. B., et al. (2018). Assessing the landscape functional connectivity using movement maps: a case study with endemic Azorean insects. J. Insect Conserv. 22, 257-265. doi: 10.1007/s10841-018-0059-7

Baselga, A. (2010). Partitioning the turnover and nestedness components of beta diversity. Global Ecol. Biogeogr. 19, 134-143. doi: $10.1111 / j .1466-8238.2009 .00490 . x$

Baselga, A. (2012). The relationship between species replacement, dissimilarity derived from nestedness, and nestedness. Global Ecol. Biogeog. 21, 1223-1232. doi: 10.1111/j.1466-8238.2011.00756.x

Baselga, A., and Orme, C. D. L. (2012). betapart: an R package for the study of beta diversity. Methods Ecol. Evol. 3, 808-812. doi: 10.1111/j.2041-210X.2012.00224.x

Bettencourt, M. L. (1979). O clima dos Açores como recurso natural na aplicação especialmente em agricultura e indústria do turismo. Lisboa: Instituto Nacional de Meteorologia e Geofísica.

Bilton, D. T., Freeland, J. R., and Okamura, B. (2001). Dispersal in freshwater invertebrates. Annu. Rev. Ecol. Evol. S. 3, 159-181. doi: 10.1146/annurev.ecolsys.32.081501.114016

Blanchet, F. G., Legendre, P., and Borcard, D. (2008). Forward selection of explanatory variables. Ecology 89, 2623-2632. doi: 10.1890/070986.1

Borcard, D., and Legendre, P. (2002). All-scale spatial analysis of ecological data by means of principal coordinates of neighbour matrices. Ecol. Model. 153, 51-68. doi: 10.1016/S0304-3800(01)00501-4
Supplementary Material 1 | Photographs of some of the study natural ponds (Supplementary Figure 1), some of the artificial tanks

(Supplementary Figure 2), and a list of the local names of the study natural ponds (Supplementary Table 1).

Supplementary Material 2 | Completeness of the pond inventories through abundance- and sample-based rarefaction curves to assess if the pond inventories are comparable in sampling efforts.

Supplementary Material $\mathbf{3} \mid$ Check-list including the relative abundance of the taxa captured during the extensive sampling. The relative abundance was calculated as the average number of individuals captured, considering the number of sampling units per pond and tank.

Supplementary Material 4 | Check-list of the captured taxa, including the number of individuals per pond and month, during the monthly sampling ("monthly sampling" spreadsheet), and the environmental variables of these ponds per sampling month ("variables monthly sampling" spreadsheet). A indicates Adult, L Larva, - Not captured. DO is dissolved oxygen concentration, EC is electrical conductivity, TP is total phosphorous concentration, and $\mathrm{Chl}$ is chlorophyll-a concentration.

Supplementary Material $\mathbf{5}$ | Independent percentage of contribution of each species to the macroinvertebrate dissimilarities detected between natural ponds and artificial tanks after a SIMPER analysis.

Borges, P. A. V., Cunha, R., Gabriel, R., Martins, A. M. F., Silva, L., Vieira, V., et al. (2005). "Description of the terrestrial Azorean biodiversity," in A List of the Terrestrial Fauna (Mollusca and Arthropoda) and Flora (Bryophyta, Pteridophyta and Spermatophyta) from the Azores, eds P. A. V. Borges, R. Cunha, R. Gabriel, A. M. F. Martins, L. Silva, and V. Vieira (Horta, Angra do Heroísmo, and Ponta Delgada: Direcção Regional de Ambiente and Universidade dos Açores), 21-68.

Borges, P. A. V., Lamelas-Lopez, L., and Amorim, I. R. (2018). Hydroporus guernei. The IUCN Red List of Threatened Species 2018:e.T97167384A99166674. doi: 10.2305/IUCN.UK.2018-1.RLTS.T97167384A99166674.en

Borges, P. A. V., Rigal, F., Ros-Prieto, A., and Cardoso, P. (2020). Increase of insular exotic arthropod diversity is a fundamental dimension of the current biodiversity crisis. Insect Conserv. Diver. 13, 508-518. doi: 10.1111/icad.12431

Borges, P. A. V., Vieira, V., Amorim, I. R., Bicudo, N., Fritzén, N., Gaspar, C., et al. (2010). "List of arthropods (Arthropoda)," in A List of the Terrestrial and Marine Biota from the Azores, eds P. A. V. Borges, A. Costa, R. Cunha, R. Gabriel, V. A. Gonçalves, F. Martins, et al. (Cascais: Princípia), 179-246.

Bossard, M., Feranec, J., and Otahel, J. (2000). CORINE Land Cover Technical Guide: Addendum 2000. Copenhagen: European Environment Agency.

Brinck, P., and Scherer, E. (1957). On the Ephemeroptera of the Azores and Madeira. Bolletin go Museu Municipal do Funchal 14, 55-66.

Campbell, B. D., Haro, R. J., and Richardson, W. B. (2009). Effects of agricultural land use on chironomid communities: comparisons among natural wetlands and farm ponds. Wetlands 29, 1070-1080. doi: 10.1672/08-141.1

Carvalho, J. C., Cardoso, P., and Gomes, P. (2012). Determining the relative roles of species replacement and species richness differences in generating beta-diversity patterns. Global Ecol. Biogeogr. 21, 760-771. doi: 10.1111/j.1466-8238.2011.00694.x

Céréghino, R., Biggs, J., Oertli, B., and Declereck, S. (2008). The ecology of European ponds: defining the characteristics of a neglected freshwater habitat. Hydrobiologia 597, 1-6. doi: 10.1007/s10750-007-9225-8

Céréghino, R., Oertli, B., Bazzanti, M., Coccia, C., Compin, A., Jeremy, B., et al. (2012). Biological traits of European pond macroinvertebrates. Hydrobiologia 689, 51-61. doi: 10.1007/s10750-011-0744-y

Collinson, N. H., Biggs, J., Corfield, A., Hodson, M. J., Walker, D., Whitfield, M., et al. (1995). Temporary and permanent ponds: an assessment of the effects of drying out on the conservation value of aquatic macroinvertebrate communities. Biol. Conserv. 74, 125-134. doi: 10.1016/0006-3207(95) 00021-U 
Corbet, P. S. (1957). The life-history of the emperor dragonfly Anax imperator Leach (Odonata: Aeshnidae). J. Anim. Ecol. 26, 1-69. doi: 10.2307/1781

Deacon, C., Samways, M. J., and Pryke, J. S. (2018). Artificial reservoirs complement natural ponds to improve pondscape resilience in conservation corridors in a biodiversity hotspot. PLOS ONE 13:e0204148. doi: 10.1371/journal.pone. 0204148

Deacon, C., Samways, M. J., and Pryke, J. S. (2019). Aquatic insects decline in abundance and occupy low-quality artificial habitats to survive hydrological droughts. Freshwater Biol. 64, 1643-1654. doi: 10.1111/fwb.13360

Declerck, S., De Bie, T., Ercken, D., Hampel, H., Schrijvers, S., VanWichelen, J., et al. (2006). Ecological characteristics of small farmland ponds: associations with land use practices at multiple spatial scales. Biol. Conserv, 131, 523-532. doi: $10.1016 /$ j.biocon.2006.02.024

DROTH (2008). Carta de ocupação do solo da região Autónoma dos AçoresProjecto SUEMAC. Secretaria Regional do Ambiente, Direcção Regional do Ordenamento do território e dos Recursos Hídricos, Ponta Delgada, Ponta Delgada.

Elias, R. B., Gil, A., Silva, L., Fernández-Palacios, J. M., Azevedo, E. B., and Reis, F. (2016). Natural zonal vegetation of the Azores Islands: characterization and potential distribution. Phytocoenologia 46, 107-123. doi: $10.1127 /$ phyto/2016/0132

Elton, C. S. (1958). The Ecology of Invasions by Animals and Plants. Methuen, London: Springer. doi: 10.1007/978-1-4899-7214-9

Engler, A. (1914). "Pflanzengeographie," in Kultur der Gegenwart, Ihre Entwicklung und ihre Ziele, eds. R. Hertwig, and R. v. Wettstein (Vierter Band: Abstammungslehre, Systematik. Paläontologie, Biogeographie. Teubner, Leipzig), 187-263.

Florencio, M. (2010). Dinámica espacio temporal de la comunidad de macroinvertebrados de las lagunas temporales de Doñana. $\mathrm{PhD}$ thesis. Estación Biológica de Doñana (CSIC), Universidad de Sevilla, Sevilla.

Florencio, M., Díaz-Paniagua, C., Gómez-Rodríguez, C., and Serrano, L. (2014). Biodiversity patterns in a macroinvertebrate community of a temporary pond network. Insect Conserv. Div. 7, 4-21. doi: 10.1111/icad.12029

Florencio, M., Díaz-Paniagua, C., and Serrano, L. (2016a). Relationships between hydroperiod length, and seasonal and spatial patterns of beta-diversity of the microcrustacean assemblages in Mediterranean ponds. Hydrobiologia 774, 109-121. doi: 10.1007/s10750-015-2515-7

Florencio, M., Díaz-Paniagua, C., Serrano, L., and Bilton, D. T. (2011). Spatio-temporal nested patterns in macroinvertebrate assemblages across a pond network with a wide hydroperiod range. Oecologia 166, 469-483. doi: $10.1007 / \mathrm{s} 00442-010-1847-2$

Florencio, M., and Lamelas-López, L. (2016). Threatened pond endemicity on an oceanic island: the presence of an exotic fish. Limnetica 35, 235-242. doi: 10.23818/limn.35.19

Florencio, M., Rigal, F., Borges, P. A., Cardoso, P., Santos, A. M., and Lobo, J. M. (2016b). The role of plant fidelity and land-use changes on island exotic and indigenous canopy spiders at local and regional scales. Biol. Invasions 18 , 2309-2324. doi: 10.1007/s10530-016-1162-x

Florencio, M., Serrano, L., Gómez-Rodríguez, C., Millán, A., and Díaz-Paniagua, C. (2009). Inter-and intra-annual variations of macroinvertebrate assemblages are related to the hydroperiod in Mediterranean temporary ponds. Hydrobiologia 634, 167-183. doi: 10.1007/s10750-009-9897-3

Foote, A. L., and Hornung, C. L. R. (2005). Odonates as biological indicators of grazing effects on Canadian prairie wetlands. Ecol. Entomol. 30, 273-283. doi: 10.1111/j.0307-6946.2005.00701.x

Fuentes-Rodríguez, F., Melchor, J., Gallego, I., Lusi, M., Fenoy, E., Leon, D., et al. (2013). Diversity in Mediterranean farm ponds: trade-offs and synergies between irrigation modernisation and biodiversity conservation. Freshwater Biol. 58, 63-78. doi: 10.1111/fwb.12038

Gabriel, R., and Bates, J. W. (2005). Bryophyte community composition and habitat specificity in the natural forests of Terceira, Azores. Plant Ecol. 177, 125-144. doi: 10.1007/s11258-005-2243-6

Gaspar, C., Borges, P. A. V., and Gaston, K. J. (2008). Diversity and distribution of arthropods in native forests of the Azores archipelago. Arquipélago Life Marine Sci. 25, 1-30.

Gaspar, C., Gaston, K. J., Borges, P. A. V., and Cardoso, P. (2011). Selection of priority areas for arthropod conservation in the Azores archipelago. J. Insect Conserv. 15, 671-684. doi: 10.1007/s10841-010-9365-4
Golterman, H. L. (1991). Direct nesslerization of ammonia and nitrate in freshwater. Ann. Limnol. 27, 99-101. doi: 10.1051/limn/1991007

Golterman, H. L. (2004). The chemistry of phosphate and nitrogen compounds in sediments. Kluwer Academic Publisher, Dordrecht, Boston, London.

Gonçalves, V. (2008). Contribuição para o Estudo da Qualidade Ecológica das Lagoas dos Açores. Fitoplâncton e diatomáceas bentónicas. $\mathrm{PhD}$ thesis. Universidade dos Açores, Ponta Delgada, Portugal.

Goslee, S. C., and Urban, D. L. (2007). The ecodist package for dissimilarity-based analysis of ecological data. J. Stat. Softw. 22, 1-19. doi: 10.18637/jss.v022.i07

Hassall, C. (2014). The ecology and biodiversity of urban ponds. WIREs Water 1, 187-206. doi: 10.1002/wat2.1014

Heyer, W. R., Donnelly, M. A., McDiarmid, R. W., Hayek, L.-A. C., and Foster, M. S. (1994). Measuringand Monitoring Biological Diversity. Standard Methods for Amphibians. Washington and London: Smithsonian Institution Press.

Hill, M. J., Biggs, J., Thornhill, I., Briers, R. A., Gledhill, D. G., White, J. C., et al. (2016). Urban ponds as an aquatic biodiversity resource in modified landscapes. Glob. Change Biol. 23, 986-999. doi: 10.1111/gcb.13401

Hill, M. J., Mathers, K. L., and Wood, P. J. (2015). The aquatic macroinvertebrate biodiversity of urban ponds in a medium sized European town (Loughborough, UK). Hydrobiologia 760, 225-238. doi: 10.1007/s10750-015-2328-8

Hughes, S. J., and Malmqvist, B. (2005). Atlantic Island freshwater ecosystems: challenges and considerations following the EU Water Framework Directive. Hydrobiologia 544, 289-297. doi: 10.1007/s10750-005-1695-y

Hykel, M., Ružičková, J., and Dolný, A. (2020). Perch selection in Sympetrum species (Odonata: Libellulidae): importance of vegetation structure and composition. Ecol. Entomol. 45, 90-96. doi: 10.1111/een.12778

Jeffries, M. J. (2003). Idiosyncratic relationships between pond invertebrates and environmental, temporal and patch-specific predictors of incidence. Ecography 26, 311-324. doi: 10.1034/j.1600-0587.2003.03348.x

Jeffries, M. J. (2005). Small ponds and big landscapes: the challenge of invertebrate spatial and temporal dynamics for European pond conservation. Aquat. Conserv. 15, 541-547. doi: 10.1002/aqc.753

Koleff, P., Gaston, K. J., and Lennon, J. J. (2003). Measuring beta diversity for presence-absence data. J. Anim. Ecol. 72, 367-382. doi: 10.1046/j.1365-2656.2003.00710.x

Legendre, P., Lapointe, F.-J., and Casgrain, P. (1994). Modelling brain evolution from behavior: a permutational regression approach. Evolution 48, 1487-1499. doi: 10.1111/j.1558-5646.1994.tb02191.x

Legendre, P., Lapointe, F.-J., and Casgrain, P. (2005). Analyzing beta diversity: partitioning the spatial variation of community composition data. Ecol. Monogr. 75, 435-450. doi: 10.1890/05-0549

McArdle, B. H., and Anderson, M. J. (2001). Fitting multivariate models to community data: a comment on distance-based redundancy analysis. Ecology 82, 290-297. doi: 10.1890/0012-9658(2001)082[0290:FMMTCD]2.0.CO;2

McKee, D., and Atkinson, D. (2000). The influence of climate change scenarios on populations of the mayfly Cloeon dipterum. Hydrobiologia 441, 55-62. doi: 10.1023/A:1017595223819

McKinney, M. L. (2002). Urbanization, biodiversity and conservation: the impacts of urbanization on native species are poorly studied, but educating a highly urbanized human population about these impacts can greatly improve species conservation in all ecosystems. Bioscience 52, 883-890. doi: 10.1641/00063568(2002)052 [0883:UBAC]2.0.CO;2

Mitsch, W. J., and Gosselink, J. G. (2000). Wetlands. 3rd Edn. New York, Chichester, Weinheim, Brisbane, Singapore, Toronto: John Wiley and Sons.

Murphy, J., and Riley, J. P. (1962). A modified single solution method for the determination of phosphate in natural waters. Anal. Chim. Acta 27: 31-36., B., and Parris, K.M. (2019). Review: toward management of urban ponds for freshwater biodiversity. Ecosphere 10:e02810. doi: 10.1016/S0003-2670(00)88444-5

Oertli, B., and Parris, K. M. (2019). Review: toward management of urban ponds for freshwater biodiversity. Ecosphere 10:e02810. doi: 10.1002/ecs2.2810

Oksanen, J., Blanchet, F. G., Friendly, M., Kindt, R., Legendre, P., McGlinn, D., et al. (2019). vegan: Community Ecology Package. R package version 2.56. Available online at: https://CRAN.R-project.org/package=vegan (accessed November 2020).

Peres-Neto, P. R., and Legendre, P. (2010). Estimating and controlling for spatial structure in the study of ecological communities. Global Ecol. Biogeogr. 19, 174-184. doi: 10.1111/j.1466-8238.2009.00506.x 
Plenzler, M. A., and Michaels, H. J. (2015). Terrestrial habitat quality impacts macroinvertebrate diversity in temporary wetlands. Wetlands 35, 1093-1103. doi: 10.1007/s13157-015-0697-4

Pyšek, P., Bacher, S., Chytrý, M., Jarošík, V., Wild, J., Celesti-Grapow, L., et al. (2010). Contrasting patterns in the invasions of European terrestrial and freshwater habitats by alien plants, insects and vertebrates. Global Ecol. Biogeogr. 19, 317-331. doi: 10.1111/j.1466-8238.2009.00514.x

Raposeiro, P. M., Mafalda Cruz, A., Hughes, S. J., and Costa, A. C. (2012). Azorean freshwater invertebrates: status, threats and biogeographic notes. Limnetica 31, 0013-22. doi: 10.23818/limn.31.02

Raposeiro, P. M., Rubio, M. J., González, A., Hernández, A., Sánchez-López, G., Vázquez-Loureiro, D., et al. (2017). Impact of the historical introduction of exotic on the chironomid community of Lake Azul (Azores Islands). Palaeogeogr. Palaeocl. 466, 77-88. doi: 10.1016/j.palaeo.2016.11.015

Reyne, M., Nolan, M., McGuiggan, H., Aubry, A., Emmerson, M., Marnell, F., et al. (2020). Artificial agri-environment scheme ponds do not replicate natural environments despite higher aquatic and terrestrial invertebrate richness and abundance. J. Appl. Ecol. 00, 1-12. doi: 10.1111/1365-2664.13738

Ruggiero, A., Céréghino, R., Figuerola, J., Marty, P., and Angélibert, S. (2008). Farm ponds make a contribution to the biodiversity of aquatic insects in a French agricultural landscape. C. R. Biol. 331, 298-308. doi: 10.1016/j.crvi.2008. 01.009

Şahin, S. K., and Zeybek, M. (2016). Distribution of Mollusca fauna in the streams of Tunceli Province (East Anatolia, Turkey) and its relationship with some physicochemical parameters. Turk. J. Fish. Aquat. Sci. 16, 187-195. doi: 10.4194/1303-2712-v16_1_19

Sala, O. E., Chapin, F. S. I. I. I., Armesto, J. J., Berlow, E., Bloomfield, J., Dirzo, R., et al. (2000). Global biodiversity scenarios for the year 2100. Science 287, 1770-1774. doi: 10.1126/science.287.5459.1770

Samways, M. J., Deacon, C., Kietzka, G. J., Pryke, J. S., Vorster, C., and Simaika, J. P. (2020). Value of artificial ponds for aquatic insects in drought-prone southern Africa: a review. Biodivers. Conserv. 29, 3131-3150. doi: 10.1007/s10531-020-02020-7

Socolar, J. B., Gilroy, J. J., Kuni, W. E., and Edwards, D. P. (2016). How should beta-diversity inform biodiversity conservation. Trends Ecol. Evol. (Amst). 31, 67-80. doi: 10.1016/j.tree.2015.11.005

Stauder, A. (1991). Water fauna of a Madeiran stream with notes on the zoogeography of the Macaronesian islands. Boletim do Museu Municipal do Funchal 43, 243-299.
Svensson, B. W. (1977). Dytiscidae and Gyrinidae (Coleoptera) from the Azores and Madeira. Boletim do Museu Municipal do Funchal. 31, 87-99.

Swartz, T. M., and Miller, J. R. (2019). Managing farm ponds as breeding sites for amphibians: key trade-offs in agricultural function and habitat conservation. Ecol. Appl. 29:e01964. doi: 10.1002/eap.1964

Thiere, G., Milenkovski, S., Lindgren, P. E., Sahlén, G., Berglund, O., and Weisner, S. E. (2009). Wetland creation in agricultural landscapes: biodiversity benefits on local and regional scales. Biol. Conserv. 142, 964-973. doi: 10.1016/j.biocon.2009.01.006

Triantis, K. A., Borges, P. A. V., Ladle, R. J., Hortal, J., Cardoso, P., Gaspar, C., et al. (2010). Extinction debt on oceanic islands. Ecography 33, 285-294. doi: 10.1111/j.1600-0587.2010.06203.x

Tuomisto, H. (2010). A diversity of beta diversities: straightening up a concept gone awry. Part 1. Defining beta diversity as a function of alpha and gamma diversity. Ecography 33, 2-22. doi: 10.1111/j.1600-0587.2009.05880.x

Urban, M. C. (2004). Disturbance heterogeneity determines freshwater metacommunity structure. Ecology 85, 2971-2978. doi: 10.1890/03-0631

Wellborn, G. A., Skelly, D. K., and Werner, E. E. (1996). Mechanisms creating community structure across a freshwater habitat gradient. Annu. Rev. Ecol. Syst. 27, 337-363. doi: 10.1146/annurev.ecolsys.27.1.337

Williams, D. D. (1997). Temporary pond and their invertebrate communities. Aquat. Conserv. 7, 105-117. doi: 10.1002/(SICI)1099-0755(199706)7:2<105: AID-AQC222>3.0.CO;2-K

Williams, D. D. (2006). The Biology of Temporary Waters. Oxford: Oxford University Press.

Williams, P., Biggs, J., Fox, G., Nicolet, P., and Whitfield, M. (2001). History, origins and importance of temporary ponds. Freshw. Forum 17, 7-15.

Conflict of Interest: The authors declare that the research was conducted in the absence of any commercial or financial relationships that could be construed as a potential conflict of interest.

Copyright (C) 2021 Lamelas-López, Borges, Serrano, Gonçalves and Florencio. This is an open-access article distributed under the terms of the Creative Commons Attribution License (CC BY). The use, distribution or reproduction in other forums is permitted, provided the original author(s) and the copyright owner(s) are credited and that the original publication in this journal is cited, in accordance with accepted academic practice. No use, distribution or reproduction is permitted which does not comply with these terms. 